\title{
The Impact of Hiv/Aids on School Enrolment as a Variable for Future Projection and In the Rationale for Physical Resource Provisioning and Prioritization
}

\author{
Maimane Ramathibela Joseph \\ jmaimane@cut.ac.za \\ Rankhumise Mmushetji Petrus \\ Central University of Technology, RSA \\ mprankhumise@cut.ac.za
}

Doi:10.5901/mjss.2014.v5n27p1264

\begin{abstract}
The impact of HIVIAIDS cuts across all sectors of economic activities and social life for example, it not only reduces the stock of human capital but also the capacity to maintain. It leaves children without parents, learners without teachers, Children end up been child headed in the families, affect families emotional and makes government poor. The required turnover of many hunted after skills and training like engineers, doctors, teachers, artisans and others. In the educational sphere, it leads to among other things a decrease in potential clientele for education resources. The workforce, its impact increases expenditure on the one hand and decreases productivity on the other. In fact, economists imagine that even when unemployment rates are high, retirement and death of a large number of skilled and unskilled workers will cause an increase in wages.
\end{abstract}

\section{Introduction}

South Africa is currently experiencing one of the most severe AIDS epidemics in the world with more than five million (or an estimated 11\%) of the population living with HIV (Claasen, 2006)For each person living with HIV not only the infected person feels, the impact but it also affects the lives of the families, friends and the community. To date over two million people have died in South Africa from AIDS related causes (The threat posed by the spread of the HIVI AIDS in South Africa and Sub-Saharan Africa, presents unprecedented challenges to the South African intellectual community of educators and learners. South Africa is no exception with regard to the escalating number of deaths caused by the epidemic.

The HIVIAIDS epidemic affects the education sector in at least three ways: the supply of education through the availability of teachers, the demand for education (total number of children and the number enrolled and staying in school ) and the quality of education (supply of experienced teachers). Because of HIVIAIDS, fewer children are able to enroll in schools and receive the basic skill and knowledge they need, fewer teachers are able to teach them, and the quality of education they receive consequently diminishes. The Department of Education (2003:5) argues that the epidemic will affect the education services and enrolment through increasing number of deaths. The epidemic will also increase the cost of providing education through the impact it has on the education system itself, the educator, the learner and on the dropout and absenteeism rates. It is in this context that both primary and secondary school learners are targeted in this study in order to find out the impact HIVIAIDS has on school enrolment in particular and on education in general. According to Whiteside (1998:1-6), HIVIAIDS affects young people, and is rapidly becoming the biggest killer of young people between the ages of 15 and 19. In this age group, people are in secondary school and are sexually active. This implies that secondary and primary school learners are adversely affected by the pandemic; hence, the problem investigated is the impact of HIVIAIDS on school enrolment.

The death of learners, teachers, and parents are affecting the school enrolment as a smaller number of learners that entering the school system and more learners are dropping out of school to take care of their sick parents. The number of learners that entering the school system is diminishes if AIDS orphans do not enroll, delay enrolling or leaving school in numbers. The absenteeism and death of teachers lead to lack of teaching and learning in appropriate time. 


\section{Theoretical Framework}

Education is a major engine of economic and social development. The expansion of educational system became a high priority for many governments in the decades following the Second World War as evidence accumulated investment in human capital, particularly health and education, had important economic benefit for the whole society, between 1970 and 2000, the percentage of the population age 15 and over who had completed primary school increased from 23 to 43 per cent in 72 developing countries (estimated by Barro \& Lee, 2000). Improvement in Sub-Saharan African countries however lagged behind most of the other regions. According to UNAIDS (2004), today HIVIAIDS has become the number one killer disease of men and women in many countries in Africa. Since the onset of HIV in 1983, over 65 million people have been infected, of whom 25 million have died and the majority of these cases are in Sub-Saharan Africa. Nowadays, HIVIAIDS is not only a health issue, but also negatively affects the education sector in many powerful ways. Hence, the problem investigated in this study is the impact of HIVIAIDS on school enrolment.

\section{Hypotheses}

There is impact of HIVIAIDS:

Communities have the knowledge and resources to lead healthy lives. The researcher focuses my efforts on communities where malnutrition is high and the need for family planning, reproductive health and HIVIAIDS awareness and education is evident. I operate in the area of schools child health and nutrition, adolescent reproductive health and HIVIAIDS. In particular, I emphasize service to at-risk populations, such as orphans and vulnerable children (OVCs) and people living with HIVIAIDS (PLHIVs). The importance of comprehensive, holistic care is strongly reflected in our program design. I do not only provide education and assistance in health care, but also take care that that the relevant resources are been supply.

With the problem statement in mind and in accordance with the aim, the following hypotheses were examined:

* Adolescents have adequate knowledge of responsible sexual behaviour.

* Adolescents have adequate knowledge of the causes and consequences of sexually transmitted diseases.

* Life Skills programmes will enhances their knowledge and help to change irresponsible behaviour. explored.

In addition to the above hypotheses, knowledge regarding safe sex practices and HIVIAIDS transmission is

\section{Purpose of Research}

Is to investigate the impact of HIVIAIDS on school enrolment physical resource provisioning in special school for the Deaf and blind in Motheo district schools whether it is grade 4-12 negative or positive. The study is also focus on the burden posed by HIVIAIDS on learners and educators who have to leave school or work to take care of their sick parents, friends or even relatives, and also to highlight to the stakeholders the prevention program, and the impact HIVIAIDS has on the education system

\section{Statement of the Problem}

The research aims to investigate the impact HIVIAIDS has on education, whereby she will make use of special school for deaf and blind. The reason is that lot of children are left orphans. Some leave school to take care of their sick parents. This can lead to fewer children will enrol in school because of HIV positive mothers that die young, with progeny (Combed 2000: 16-17) indicates that in future, i.e. children are dying of AIDS complications, and children who are ill, impoverished, orphaned, caring for younger children, or earning and producing, stay out of the system.

\section{Research Objectives}

The objective of this research is to:

Determine the impact of HIVIAIDS on education in general: Establish the impact of HIVIAIDS on education and as perceived by learners on enrolment, provisioning and prioritization in intermediate schools in Motheo District and for future physical resource.

Investigate how the impact of HIVIAIDS on education can be alleviated. 


\section{Questions to be Answered}

* How can the impact of HIVIAIDS on education for future physical resource provisioning and prioritization be alleviated?

* Has the education system adopted changes because of the epidemic in terms of system level and school level policies, including changes in the curriculum?

* What is the impact of HIVIAIDS on education as perceived by learners in Motheo District?

- What is the impact of HIVIAIDS epidemic on teacher / learner absenteeism?

* Do orphans tend to have learning barriers at school because of HIVIAIDS more than other children do?

\section{Literature Review}

In the mid 1970s, the scientific community first became aware of an illness that was striking predominantly adults in various parts of the world. Those affected by the disease would gradually waste away and not respond well to the treatment of common illnesses. It was not until the early 1980s that the syndrome was identified as the Acquired Immune Deficiency Syndrome (AIDS), a clinical syndrome that is a group of various illnesses that together characterized as a disease resulting from damage to the immune system leading to the final and fatal stage of the infection of Human Immunodeficiency Virus (HIV).

HIVIAIDS epidemic has the potential to affect schools in the following ways: reduction of demand for schooling among children and adolescents of school going age; reduction in supply of teaching services due to educator absenteeism, illness, medical boarding because of ill-health, and death, reduction of availability of educational resources because the Department of Education spends more money on HIVIAIDS than on schools' material resources; the need for schools to socially adjust in response to the special needs of a rapidly increasing number of learner orphans as a result of the HIVIAIDS epidemic. It is clear that the impact of HIVIAIDS epidemic on school enrolment can bring many changes to the school system.

At the same time, HIVIAIDS pandemic is destroying families who are producers of children who form the primary clientele of schools. More and more learners and adolescents may drop out of schools as result of the epidemic.

\subsection{Historical Backgound Of Hiv/Aids}

HIVIAIDS is defined as a disease caused by a latent, slow-acting virus known as the Human Immunodeficiency Virus (HIV). The virus is said to destroy parts of the body's immune system, leaving the victim without defenses against certain cancers and infections. AIDS is an acronym for Acquired Immunodeficiency Syndrome or Acquired Immune Deficiency Syndrome, which Visagie (1999: 137) defines it as a collection of symptoms and infections resulting from the depletion of immune system caused by infections with the Human Immunodeficiency Virus (HIV). HIV is a very small germ or organism which infects people through contact with infected body fluids (Karim, 2000: 291). It cannot be seen by the naked eye but can only be detected under an electronic microscope (Kaplan, Jaffe, Masur, Decock and Holmes, 2000: 14). HIV can only survive and multiply in body fluids such as sperms, vaginal fluids, breast milk and saliva (Macintyre, 2000: 24).

HIV attacks the immune system that serves as the body's defence mechanism against infection and reduces the resistance of the body to all kinds of illnesses like influenza, diarrhea, pneumonia, Tuberculosis (TB) and certain cancers. HIV eventually weakens the body to such an extent that it cannot fight sicknesses and causes death after a period of approximately five to ten years after being infected, but some HIV victims live longer if they receive the right psychocounseling and medication (Kelly, 2004: 80). This means that this malady attacks the immune system that protects that body from illnesses and it damages the ability of the body to protect itself from TB, chest infections, sores, upset stomach and other infections after the immune system had been weakened by this fatal HI virus (Cross, 2001: 132; Amogne \& Abukart, 2002: 400).

After many years, the damages are serious and the person contracts serious illnesses which develop to a syndrome known as AIDS, which is a final stage of the HIV (Desmond, Michael and Gow, 2000: 44).

\subsection{The Impact of HIVIAIDS on Education}

HIVIAIDS has a negative impact on education. According to Whiteside 1998: 16), HIVIAIDS may have the following negative impacts on education: affect learners' performance in class, learners' school enrolment, educator's dedication to 
work, learner drop-out rates, increase in poverty and orphanage rates, as well as the quality of education being delivered and the provisioning of resources.

\subsection{Supply and demand of education provisioning}

Educational staff at all levels will probably experience increased levels of illness and death amongst themselves as it is happening in the general population. Therefore HIVIAIDS impacts negatively on teaching service in terms of replacement and redeployment, absenteeism, illness and deaths

\subsection{Demands on Education}

The number of school enrolments is lower than, would be the case in the absence of HIVIAIDS. This decline in numbers of school enrolment will, over time, work its way up the education system resulting in children being out of school because the child labor is required at home, or because there are no resources provided for to send them to school.

\subsection{Provisioning of Education}

The curriculum should make provision for HIVIAIDS education and also look at the special needs of those affected and infected by the disease. This therefore implies that there will be a shift of resources from material provisioning to caring for the sick. Whiteside (1998: 16-17) confirms the idea that it is likely the education sector may be at risk for it is both susceptible and vulnerable to HIVIAIDS because of its nature.

The implications of HIVIAIDS on education are far reaching with regard to the availability of children to be educated and preparation for future manpower needs. Coombe (2000: 14), says that studies show that since 2000, the proportion of potential parents (20-40years) is decreasing; the number of orphans is increasing while poverty levels and drop-out rates at schools are also increasing owing to the pandemic

\subsection{Educator mortality}

The HIVIAIDS status in South African schools is appalling, hence the research is dealing with HIVIAIDS affected and infected educators in schools is of paramount importance.

Application of HIVIAIDS adult prevalence estimates suggest that out of approximately 31600 primary school educators in 1996/97, some 6300 (20\%) were HIV positive. This is in line with the international findings of a positive correlation between educational status and HIV-risk (Macphail, Campbell, Williams \& Van Dam, 2000: 14).

\section{Methodology}

\subsection{A smaller supply of educational facilities and human resources}

Rosen, Simon, Thea and Vincent (2000: 133) state that it seems likely that an absolute or relative decrease in the number of learners, either through initial enrolment or through higher drop-out or non-continuation rates, will lead to a similar decrease in the number of classes and schools. Fewer learners in the system and lower demand for places in education programmes may lead to smaller supply of educational facilities and places. Schools that have enrolments below a certain minimum may therefore be closed and the remaining learners be moved to other schools. More complex solutions such as the introduction of -multi- grade teaching might tax both the finance and flexibility of affected school systems. Another possible reason for smaller supply of educational facilities may be the lack of support and financing from the community and the government (sheared \& Kakabadse, 2002: 140). They will both have other competing, noneducational demands for their resources and therefore funds for maintaining current facilities and places, let alone building new ones may be very limited.

Even if educational facilities continue to be available, there may be a lack of educators and other personnel like principals, supervisors and inspectors to maintain previous levels of educational services in terms of either quantity or quality (Smit \& Cronje, 2002: 47). These people may be absent from work because of illnesses, attending funerals and caring for the ill. 


\section{Pilot Study}

The study has taken place at special school for the Deaf and Blind, as it aims to study the potential impact of HIVIAIDS on education. The focus was on grade 4-12 learners at special school in Motheo District. Learners come from different province to study at a special school for the Blind and deaf. Teachers were also interviewed.

\section{Population and Sample}

The researcher has simple randomly learner from deaf and blind sections at a special school. The learners were not selected according to their performance. They were selected using their class list, whereby one of every three was selected randomly. The grades which were involved are grade 4-12grade. The sample has comprised $10 \%$ of the 25 learners at a special school in Motheo District.

\subsection{Research sample}

The sample of this study consists of educators, learners from grade 4-12 and a school management team of a special school for the Deaf and Blind in Motheo Dlstrict. Sample selection is the primary technique used to collect data and the manner in which cases information presents itself.

\subsection{Data collection}

The research instrument

The researcher used questionnaires as this is a simple way or technique to gather and interpret information in a quantitative manner. The purpose for choosing questionnaires is that, they are easy to compile and inexpensive. Questionnaires consist of a variety of instruments in which the subject responds to written questions to elicit reactions, beliefs and attitudes

The questionnaire used in this study comprises of TRUE/FALSE statements and Strongly Disagree, Disagree, Agree and Strongly Agree options. Lists the following advantages of using a questionnaire:

* Easy to administer

* Are quick to fill in

* Retain relevance of questions

* Are easy to follow up and

* Provide comparisons of group and individuals.

Mouton (2001: 103) indicates that questionnaires have some disadvantages which researchers need to take into consideration when planning the questions. The following are considered to be disadvantages:

* Not piloting or pretesting

* Words are too vague or ambiguous to respondents

* There are leading questions

* There term order effects, the order sequence of a question may affect response rates, and

* Questions measure constructs or attitudes that do not exist.

Questionnaires are used in this study because they help to glean information from a large number of people. De Vos, Strydom, Fouche and Dlport (2002: 175) state that before the researcher can decide on the nature of questionnaire, there must be clarity on precisely what information is to be obtained. The questionnaire must be brief, include those questions that are absolutely necessary for collecting all relevant information.

Part one of the questionnaire consists of TRUE/FALSE questions and general information like gender and Grade. Part two, which forms the main part of the study, investigates the impact of HIVIAIDS on school enrolment on education.

\subsection{Data processing and Analysis}

Quantitative data in professional research can be analyzed manually or by a computer (De Vos et al, 2002: 222-223). In the following section, we are going to distribute questionnaires and analyze the data received in a manual way, i.e. counting the number of responses received. 


\section{Part A}

\section{Data Analysis from Part a}

Primary School Learners

\begin{tabular}{|c|c|c|c|c|c|c|}
\hline & Number & True & False & Total & $\%$ & Total\% \\
\hline Males & 138 & 71 & 67 & 138 & 92 & 95.3 \\
\hline Females & 148 & 75 & 73 & 148 & 98.6 & \\
\hline Total & 286 & 146 & 140 & & & \\
\hline
\end{tabular}

From the above table, 150 questionnaires were issued out, of which 71 males and 75 females who submitted questionnaires agree that HIVIAIDS had a negative impact on school enrolment. Overall number of learners who agreed is 146 and this shows that four questionnaires were not returned. Out of the 150 questionnaires circulated, 140 of them answered NO to the questions and 10 questions were not returned. There was an overall of 95.3\% respondents.

\section{Part B}

Data Analysis from Part B

Secondary School Learners

\begin{tabular}{|c|c|c|c|c|c|c|}
\hline Gender & Strongly Disagree & Disagree & Agree & Strongly Agree & Total & Total \% \\
\hline Males & 259 & 382 & 301 & 143 & 1085 & 13.8 \\
\hline Females & 260 & 483 & 308 & 158 & 1164 & 12.8 \\
\hline Total & 519 & 820 & 609 & 301 & 2249 & \\
\hline
\end{tabular}

From the above data collected, it is evident that secondary school learners are quite aware of the impact of HIVIAIDS on school enrolment because they are at a mature stage of teenage hood. They are also sexually active as they are involved in sexual relationships. Out of the 15 questions about their perception about HIVIAIDS on school enrolment, 301 learners strongly agree with the statements about the impact which HIVIAIDS has on school enrolment as a variable factor for future prioritization and provisioning. They will encourage these learners who are sexually active to also use contraceptives such as condoms, abstinence and other forms of prevention.

\section{Limitation of the Study}

The learners who answered the questionnaires are from grade 4-6, 7-9 and 10-12, which poses a problem to the research study about the learners' perception and knowledge about HIVIAIDS.

According to Tonks (1996: 4), secondary school teenagers have a high level of sexual activity with multiple partners and therefore have all the risk factors. The area of study may hamper the progress of the research process because there is diversity being location, religion and culture in terms of the population of South Africa.

From this study, it means that people should be advised to use preventative methods of sexual relationships like the use of condoms and refrain from unprotected sexual intercourse. The most affected are the youth, especially educators and learners. Hence the HIVIAIDS pandemic have a severe impact on school enrolment and education.

It is clear that the following matters have been derived from this study:

* School enrolments are declining

* Drop-out rates are rising

* Absenteeism increasing

* Educators are also affected by HIVIAIDS

* Educators' performance is affected

* Learners' performance is also affected by HIVIAIDS

* Orphans go to school without food

The study achieved its aims of identifying the impact of HIVIAIDS on education, and this impacted on illnesses, absenteeism and deaths, declining performance, stress and so on. The impact of HIVIAIDS on school enrolment can therefore be described in terms of increased absenteeism and drop-out rates. 


\section{Research Design and Research Programme}

\subsection{Aim of the Research}

A non-experimental mode of inquiry is used in this research. This mode (McMillan and Schumcher, 2001: 33) describes something that has occurred or examines relationships between things without any direct manipulation of conditions.

The purpose of the research design was to find the most valid, accurate answers to the research questions, namely:

* How much knowledge and understanding do adolescents (Grade 7-12) have of responsible sexual behavior and the dangers of sexually transmitted diseases?

* What is the present situation in the Free State concerning adolescents' attitudes and beliefs on sexual behavior?

* Has the implementation of the Life Skills programmes succeeded in changing adolescents' knowledge and awareness of responsible sexual behavior and whether their behavior has changed in any way?

\subsection{Reseach Method}

\subsubsection{Quantitative research}

The quantitative part of the research is reflected here. The goal of this type of research is to provide statistical descriptions, relationships and explanations. It provides a detailed narrative description, analysis and interpretation of phenomena. (De Vos 1998: 15) refers to (Leedy 1993 :), who states that qualitative and quantitative differs mainly in the format of research in which data is obtained.

Qualitative research is usually verbal while quantitative is numerical. In quantitative research, the researcher is objective and doesn't use own interpretation. Data collection focuses on frequency. For the sake of validity and reliability, qualitative measurement was also brought into this research. A questionnaire based in the literature study was used as initial research instrument.

The questionnaire was finalised after meticulous writing, editing and review. Simple language was used as far as possible, because the survey respondents had variety backgrounds. It was not assumed that everyone had the same understanding of the facts or a common knowledge base. The questionnaires were in English only as the learners who participated were Afrikaans, English, Sesotho, Tswana, IsiXhosa and IsiZulu speakers. A preliminary test was undertaken on six respondents by means of pilot study where participation was on voluntary basis. The respondents explained what the question meant to them and whether it was valid to the questionnaire or not. In response to the feedback received from these respondents, certain modifications to the questionnaires were made.

Survey forms were circulated to schools. Questionnaires were distributed amongst learners to complete. Ethical considerations were stressed and participation in the research was anonymous as respondents were instructed not to write their names on the questionnaires. In addition, assurance was given that the data would be treated as strictly confidential. The respondents knew clearly the purpose of the questions and all questions were limited to a set of choices where one answer would be correct.

A random test sample was obtained in Motheo District of the Free State. The target group was learners from grade 7 to 12 in the age group of 14 to 19. The mean age was 15 years. Learners in grade 7 to 12 were selected as the eligible study population because of the large sample. It is safely presumed that the respondents represented the current adolescents in the Free State. The population correlated with racial/ethnic similarity in schools in Motheo District.

\subsection{Validity and Reliability}

In the context of research design, the term validity means the degree to which scientific explanations phenomena match the realities of the world (McMillan \& Shcumacher, 2001: 167). Validity is accuracy, measuring and worthiness of research project in totality. It is the degree to which the study describes measure and explains the phenomenon that it sets out to describe and explain (Willig, 2001: 16). The validity of qualitative studies can be enhanced when data is gathered in natural settings.

A combination of strategies was used in this research. Prolonged field work in the life world of learners was done. Participant observation and in-depth interviews as follow-ups to the information gained from the questionnaire reflected the reality of the life of participating adolescents. The lengthy data collection period provided opportunities for the interim 
data analysis, preliminary deductions and corroboration to refine results.

The multi-method strategy of using questionnaires, and in-depth focus group interview participant observation permitted triangulation of data and increased the credibility of the findings.

Data can be regarded as reliable if the same results are obtained when the study is repeated in other periods of time. Willig (2001: 17), however, poses that qualitative researchers do not regard reliability as of utmost importance. The aim of qualitative study is to describe and explain a specific phenomenon in as much detail as possible. The aim is seldom to generalise results to an entire population.

The extent to which the participants agreed about the phenomenon of AIDS, their knowledge on contracting or avoiding the disease and all other relevant problem areas, is so conspicuous in this study that there is definite consistency in the findings. It is impossible to predict that this performance and behaviour will be equaled by other adolescents in other periods of time. It is however possible to deduct that the tendency showed here, will be much the same in all areas in South Africa at this point in time.

\subsection{Synthesis}

By presenting both qualitative and quantitative research, a deeper understanding, knowledge and appreciation of the learner's conceptual framework was gained. The data obtained indicated amongst others that a definite need for appropriate information regarding the advantage and limitations of condoms is necessary as well as the need to reinforce general knowledge on HIVIAIDS.

\subsection{Analysis and Interpresentation of Findings}

The methods of collecting, analysing and interpreting data obtained in the investigation will be discussed in this chapter. The focus is on the extensive literature review undertaken before the investigation and the fact that the questionnaire implementation and processing of acquired data transpired before the qualitative semi-structured group interview.

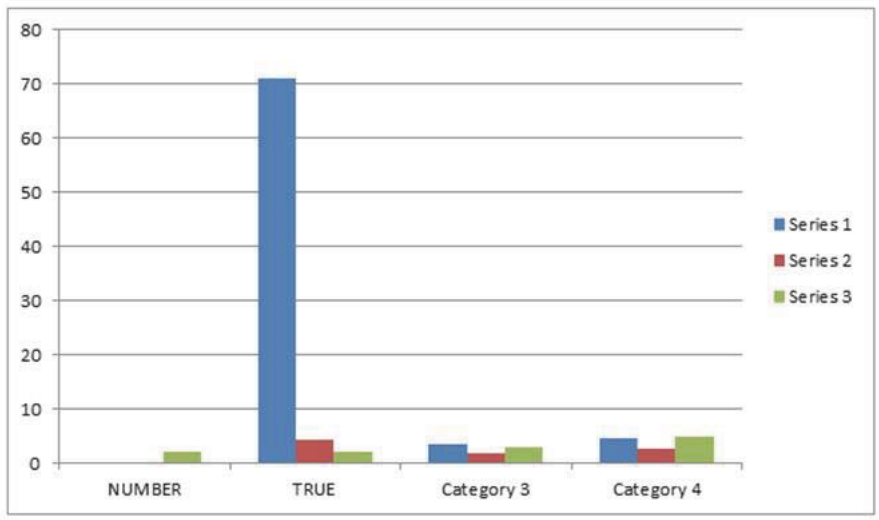

From the above table, 150 questionnaires were issued out. Of the male learners who submitted the questionnaire, 71 agree that HIVIAIDS has a negative impact on school enrolment and 75 female learners agree that HIVIAIDS has an impact on school enrolment. Overall number of learners who agreed is 146 and this shows that four (4) of the questionnaires were not returned. Out of 150 of the questionnaires, 140 of them all answered no to the questions and 10 questionnaires were not returned. The overall percentage of respondents was 95, 3. 


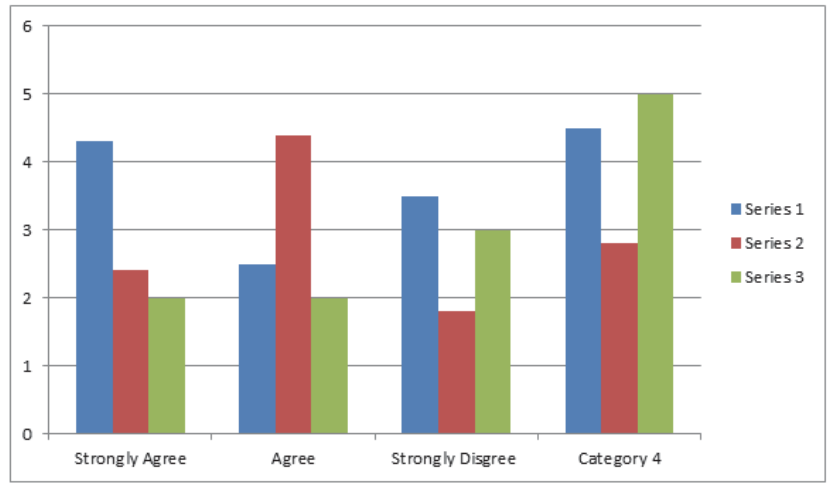

Respondents differentiate on the basis of gender in secondary school

From the above data collected, it is evident that secondary school learners are quite aware of the impact of HIVIAIDS on school enrolment as they are at a mature teenage stage. They are also sexually active. They are the ones who are involved in sexual relationships. Out of 150 questionnaires that were issued, out of the 15 questions about their perceptions on HIVIAIDS on school enrolment, 301 strongly agree with the statements about the impact of HIVIAIDS on school enrolment as a variable for future prioritasation and provisioning. They will advise these learners who are sexually active to also use contraceptives such as condoms, abstinence and other forms of prevention.

Mean age of respondents was 12 but age ranged from -13 to $18+.8 \%$ of the participants were $18+$ years. A mistake was made when presumed that learners in grade 7 would be 13 years old and $17 \%$ of the respondents did not indicate age presumably because provision was not made for learners younger than 12 years.

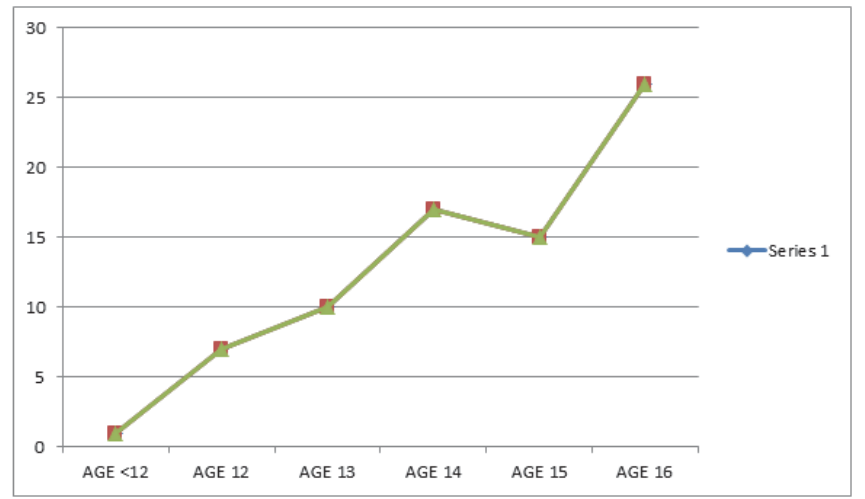

Respondents on the basis of age

\subsection{Summary from literature review research proceeding}

Researchers also posited that HIVIAIDS epidemic has a potential to affect schools in the following ways:

* Reduction in demand for schooling among children and adolescents of school age;

* Reduction in the supply of teaching services due to educator absenteeism, illness, medical boarding because of ill-health and death;

* Reduction in availability of educational resources because the Department of Education spends more money on HIVIAIDS than school's material resources;

* The need to organise schools systematical

* The need to modify curriculum to meet the needs of an HIVIAIDS era;

* The need to adapt to new social interactions both within and between the schools and communities.

The literature also highlighted that the HIVIAIDS epidemic is destroying families which are producers of children who form the primary clientele of schools as learners. As the number of families who have their structure undermined and destroyed by the impact of HIVIAIDS epidemic increase more and more learners and adolescents drop-out of school which thus impact on school enrolment. 


\section{Findings from Research}

The deduction can be made that adolescents' knowledge is still distorted and they still need to learn morals and values. Sexual and moral licentiousness are prevalent and the moral crisis in South Africa is severe. It appears as if adolescents are not concerned about what is happening around them regarding the result of licentious behaviour.

The researchers can further deduce that drugs are freely available to adolescents and this puts them in risk. They have impaired moral judgement and exaggerated emotions which contribute to sexual licentiousness.

\section{Conclusion}

From the study, it is clear that HIVIAIDS impacts negatively on school enrolment. This study further established, through literature review and questionnaires that HIVIAIDS have a devastating impact on education. It can be concluded here that evidence from literature review is supplemented by evidence from questionnaires.

The pandemic affects education, the educator, the learner as well as teaching and learning in general.

The following symptoms were derived from the research as a result of HIVIAIDS:

* School enrolments are declining

* Dropout rates are rising

* Absenteeism is increasing

* Educators are also affected and infected by HIVIAIDS

* Educators' performance is also affected

* Learner performance is also affected

* Orphans go to school without food

The study achieved its aim of establishing the impact of HIVIAIDS on education and the above symptoms are the impact HIVIAIDS on education.

\section{Recommendations}

From this study, it means that people should be advised to use preventative methods of sexual relationships like using a condom or refraining from unprotected sexual relationships.

The department of Education should work hand in glove with Department of Health as the latter department is specialist in the theme.

AIDS education should be included in all academic years of school.

\section{Bibliography}

Barnett ,T.,Tonny,P.,Whiteside,A.2002.Aids in the Twenty-First Century. New York: Palgrave MacMillian Baroo A , LEE J,Orphans.2003 living with HIV/AIDS and Living positively London .Academic Publications. Bloom,D.2000. The economics of HIV and AIDS: The case of South Africa and. London: Falmer Press. Boozer, M., Philipson, T.2000. The impact of public testing for human immunodeficiecyvirus , Journal of human resource,35(3)419-446. Catalan, J. 2000: The impact of AIDS:Pschological and social aspect of HIV infection . Amsterdam: Harwood Academic Publications. Cohen, M.L., Manion, L., \& Morrison, K.2002. Research methods in education.5thed .Cornwall: Routlegde. Cross, 2001: 132; Amogne \& Abukart, 2002: 400. Economic impact of HIV epidemic.New York : UNDP. Department of Education.2003.HIV and AIDS in your school: what parents need to know? Pretoria: Government. Printers .

Desmond, Michael and Gow, 2000: AIDS and education assessment 'exploring the implication of the HIV/AIDS epidemic. Campaign team for Africa

Devos , A.S. , Strydom, H. , Fouche , C.B. \& Delport , C.S.L. 2002 . Research at grass roots: For social science and human service professions. $2^{\text {nd }}$ Ed. Pretoria; Van Schaik.

Harrison, J. 2000. Sex-education in secondary schools. Philadelphia: Open University Press.

Hope, J.1999. Strengthening national capacity for HIV/AIDS strategic planning. New York: UNDP.

Imenda, S.N. \& Muyagwa, M.M. 2000. Introduction to research in education and behavioural science .Umtata: Einmed Publishers.

Kaplan, J. Jaffe, M.,Masur, C.,Decock, V., Holmes, F. 2000. Alternative strategies for education:; Macmillan.

Kelly, A. 2000. The social consequences of HIV/AIDS in Africa. London: SCF Publications.

Khan and Shea: 2007.Education for Development .African Development Series No.4 Kampala: Foundation for African Development.

Kippax,P. Smith,T. Aggleton, B. 2000. The impact of HIV/AIDS and sexual education on the sexual behaviour of young people. UNAIDS. Macphail, Campbell, Williams \& Van Dam, 2000. Living positively .London. National Children's Bureau.

Rosen, N., Simon, H.,Thea,S., Vincent,K . 2000. Education of with HIV infection, Washington DC.: USA 
Walker, R. 1993 .Doing research: a handbook for teachers. London: Cabridge.

Whiteside, A., \& Sunter, C.200. AIDS. The challenge for the South Africa. Tafelberg : Human and Rosseau.

(www.mg.com.za-Accessed 25 May 2007).15 April 2011]. 